\title{
Correction to: Management of industrial high-pressure fluid injection injuries (IHPFII): the Water Jetting Association (WJA) experience with water driven injuries
}

\author{
Sancho Rodríguez-Villar ${ }^{1}\left[\right.$ Robert Charles Kennedy $^{2} \cdot$ Martino Dall'Antonia $^{3} \cdot$ Carlos Pilasi Menichetti $^{1}$
}

Published online: 26 April 2019

○) Springer-Verlag GmbH Germany, part of Springer Nature 2019

\section{Correction to: \\ European Journal of Trauma and Emergency Surgery https://doi.org/10.1007/s00068-019-01106-4}

The original version of this article, unfortunately, contained three mistakes:

1. The abbreviation psi was incorrectly explained. The correct explanation is:

“psi Pounds per square inch".

2. The legend of Fig. 3 contained a part $\mathrm{c}$ where only parts a and $b$ should be given. The correct legend of Fig. 3 should read:
Fig. 3 a The patient was admitted to hospital after an accident cleaning concrete, he underwent an urgent decompression and extensive debridement, the wound left open and had three more consecutive and increasingly extensive surgical explorations at incident plus 1 day and incident plus 4 days. b Forearm and hand after almost 1 year elapsed time from an accident and after two plastic surgery reconstructions requiring an abdominal flap.

3. In Fig. 6, in the section of "Antimicrobial prophylaxis", "Patient presenting for immediate debridement after HPWJ injury $<\mathbf{2 4}$ h", "Alternative for penicillin allergic patients" the word "Meropenem*" needs to be replaced by "Metronidazole". Please find the corrected Fig. 6 below.
Sancho Rodríguez-Villar sancho.villar@nhs.net

Robert Charles Kennedy robert@waterjetting.org.uk

Martino Dall'Antonia

mdallantonia@nhs.net

Carlos Pilasi Menichetti

cpilasi@nhs.net

1 King's College Hospital NHS Trust Foundation, Denmark Hill, Brixton, London SE5 9RS, UK

2 The Water Jetting Association, Thames Innovation Centre, 2 Veridion Way Erith, Kent DA18 4AL, UK

3 Lewisham and Greenwich NHS Trust Foundation, Stadium Rd, Woolwich, London SE18 4QH, UK 


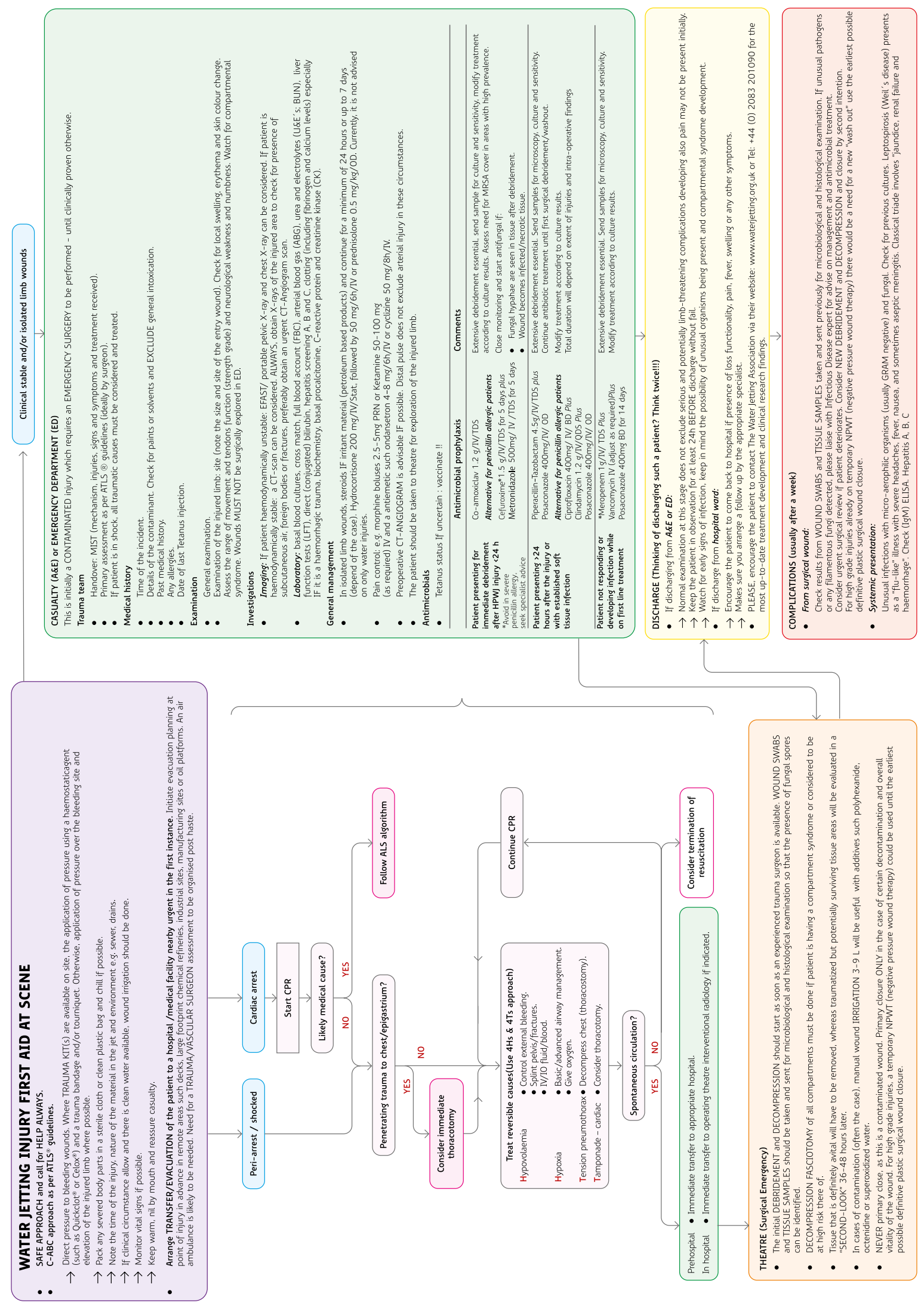

